Check for updates

Cite this: RSC Adv., 2019, 9, 1517

Received 12th October 2018

Accepted 8th January 2019

DOI: $10.1039 / c 8 r a 08462 a$

rsc.li/rsc-advances

\title{
Explosives sensing using Ag-Cu alloy nanoparticles synthesized by femtosecond laser ablation and irradiation $\uparrow$
}

\begin{abstract}
Moram Sree Satya Bharati, Byram Chandu and S. Venugopal Rao (D) *
Herein we demonstrate the synthesis of $\mathrm{Ag}-\mathrm{Cu}$ alloy NPs through a consecutive two-step process; laser ablation followed by laser irradiation. Initially, pure Ag and Cu NPs were produced individually using the laser ablation in liquid technique (with $\sim 50$ femtosecond pulses at $800 \mathrm{~nm}$ ) which was followed by laser irradiation of the mixed $\mathrm{Ag}$ and $\mathrm{Cu}$ NPs in equal volume. These $\mathrm{Ag}, \mathrm{Cu}$, and $\mathrm{Ag}-$ $\mathrm{Cu}$ NPs were characterised by UV-visible absorption, HRTEM and XRD techniques. The alloy formation was confirmed by the presence of a single surface plasmon resonance peak in absorption spectra and elemental mapping using FESEM techniques. Furthermore, the results from surface enhanced Raman scattering (SERS) studies performed for the methylene blue (MB) molecule suggested that $\mathrm{Ag}-\mathrm{Cu}$ alloy NPs demonstrate a higher enhancement factor (EF) compared to pure Ag/Cu NPs. Additionally, SERS studies of Ag-Cu alloy NPs were implemented for the detection of explosive molecules such as picric acid (PA $-5 \mu \mathrm{M}$ ), ammonium nitrate (AN -5 $\mu M)$ and the dye molecule methylene blue (MB $-5 n M)$. These alloy NPs exhibited superiority in the detection of various analyte molecules with good reproducibility and high sensitivity with EFs in the range of $10^{4}$ to $10^{7}$.
\end{abstract}

\section{Introduction}

During the last decade bimetallic/alloy nanoparticles (NPs) have gained attention in diverse fields such as photonics, catalysis, solar cells, information storage and surface-enhanced Raman scattering/spectroscopy (SERS) ${ }^{1-6}$ because of their outstanding optical and opto-electronic properties compared to those of the individual/pure metals (e.g. $\mathrm{Au}, \mathrm{Ag}$ and $\mathrm{Cu}$ ). Several methodologies have been reported to fabricate alloy NPs during the past few years, such as wet chemical methods, ${ }^{7}$ electro-deposition, ${ }^{8}$ ion beam mixing, ${ }^{9}$ ball milling and laser ablation in liquids (LAL). ${ }^{10}$ Amongst all the above-mentioned techniques, LAL has been proven to demonstrate enormous potential for producing novel material structures without the need of any further reagents/reactants, which are generally difficult to create using conventional methodologies. NP generation through LAL is quite a complex phenomenon in which several mechanisms transpire when intense laser pulses are focused on to the material, such as plasma formation, shockwave generation, formation and collapse of the cavitation bubble followed by nucleation and growth of the NPs. These processes transpire in

Advanced Centre for Research in High Energy Materials (ACRHEM), University of Hyderabad, Prof. C. R. Rao Road, Hyderabad 500046, Telangana, India. E-mail: soma_venu@uohyd.ac.in; soma_venu@yahoo.com

$\dagger$ Electronic supplementary information (ESI) available. See DOI: 10.1039/c8ra08462a various time scales starting from few picoseconds to few hundreds of microseconds. LAL has been established to be an effective approach to synthesise various bimetallic/alloy nanostructures (NSs) and NPs simultaneously. ${ }^{11-13}$ The size, shape, crystallinity, and compositions of NPs can be influenced by several experimental parameters during the synthesis process. Generally, alloy NPs can be achieved using the single step or multi-step laser ablation procedures (i) laser ablation of bulk alloy target dipped in liquid or (ii) irradiation of metal target in the presence precursor solutions $\left(\mathrm{HAuCl}_{4} / \mathrm{AgNO}_{3}\right)$ or (iii) laser irradiation of colloidal mixtures prepared individually. Byram et al. have recently demonstrated the $\mathrm{Ag}-\mathrm{Au}$ alloy NPs fabrication from the bulk alloy using fs laser irradiation. ${ }^{\mathbf{1 4}}$ Chen et al. described the Ag-Au alloy NPs fabrication through the irradiation of gold-silver colloidal mixture. ${ }^{15}$ Ganjali et al. demonstrated the synthesis of $\mathrm{Au}-\mathrm{Cu}$ alloy NPs utilising a two-step laser irradiation procedure. ${ }^{\mathbf{1 6}}$ Messina and co-workers described the mechanism in the Au-Ni alloy NPs formation based on the laser-induced melting. ${ }^{17}$

SERS technique has developed into one of the promising detection techniques because of its unique fingerprint capability, non-destructive nature and single molecule sensing ability. The enhancement obtained in the SERS signal has contributions from two mechanisms (a) electromagnetic enhancement (EM) (b) chemical enhancement (CE). EM arises from the localized surface plasmon resonance on the surface of metal nanostructure resulting in the amplification of scattered 
and incident field intensity. The $\mathrm{CE}$ also can contribute to the overall enhancement, which results from the charge transfer between the molecule and nanoparticle. ${ }^{18,19}$ Due to their efficiency and selectivity to identify trace quantities of various molecules, SERS substrates are used as sensors to detect the numerous hazardous molecules (dyes, pesticides, explosives). ${ }^{20,21}$ Recently, laser-generated alloy nanomaterials have stimulated considerable attention in SERS related applications because of their wide range of tunable optical properties based on their composition of constituents. Podagatlapalli et al. reported the detection of explosive molecules (NPZ and FOX-7) using three different compositions of Ag-Au bimetallic NPs/ NSs achieved by femtosecond (fs) laser ablation of a bulk Ag$\mathrm{Au}$ target in acetone. ${ }^{22}$ Amendola et al. have studied the SERS activity of magnetically assembled Ag-Fe NPs fabricated with nanosecond ablation. ${ }^{23}$

In earlier studies, the antibacterial activity of $\mathrm{Ag}$, Cu NPs was exploited in various fields such as medicine, water treatment and food processing. ${ }^{24-26}$ However, $\mathrm{Ag}-\mathrm{Cu}$ alloy NPs have rarely been utilized in SERS based detection/sensing. The potential advantage of $\mathrm{Ag}-\mathrm{Cu}$ NPs is the enhanced structural stability with reduced oxidation (in comparison to pure $\mathrm{Ag} / \mathrm{Cu} \mathrm{NPs}$ ) as revealed from theoretical studies of Shin et al. using density functional theory (DFT). ${ }^{27}$ The presence of Ag could effectively prevent the $\mathrm{Cu}$ NPs from oxidation and furthermore increase the stability. ${ }^{7}$ The low cost incurred with such alloy NPs due to abundant availability of $\mathrm{Ag}$ and $\mathrm{Cu}$ compared to $\mathrm{Au}$ is also an added advantage. Chang et al. reported the improved SERS efficiency of $\mathrm{Ag}-\mathrm{Cu}$ nanodendrites $(\sim 2.6$ fold higher peak intensity compared to a $\mathrm{Ag}$ nanodendrite for rhodamine $6 \mathrm{G}$ molecule). ${ }^{28}$ Most of the reported Ag-Cu alloy NPs based SERS substrates are synthesized from various chemical approaches. Li et al. showed a significant enhancement in SERS (4-MBA) signal by the bimetallic $\mathrm{Cu}-\mathrm{Ag}$ nanodendrite substrate compared to $\mathrm{Ag}$, and $\mathrm{Cu}$ fabricated with electrodeposition method. ${ }^{8}$ Lee et al. demonstrated the superior SERS (R6G) performance of raspberry-like Ag@Cu bimetal nanoparticles synthesised from stepwise reduction process. ${ }^{29}$ In our earlier study, Ag@Au and Cu@Au alloy NPs were fabricated by laser ablation of $\mathrm{Ag} / \mathrm{Cu}$ target in precursor and the SERS (MB, PA and DNT molecules were studied) performance of Ag-Au alloy NPs was found to be superior to the $\mathrm{Cu}-\mathrm{Au}$ alloy NPs. ${ }^{30}$ To the best of our knowledge, the utility of laser-synthesized $\mathrm{Ag}-\mathrm{Cu}$ alloy NPs as SERS substrates for the detection of explosive molecules has not been reported till date. Herein, we report the synthesis of $\mathrm{Ag}-\mathrm{Cu}$ alloy NPs through a consecutive two-step process, laser ablation followed by laser irradiation. We produced the $\mathrm{Ag}-\mathrm{Cu}$ alloy NPs by irradiation of mixed $\mathrm{Ag}$ and $\mathrm{Cu}$ colloidal solution (1:1 ratio) obtained separately through the LAL process. Furthermore, the SERS activity of these NPs was tested with the dye molecule methylene blue (MB) and explosives such as picric acid (PA) and ammonium nitrate (AN).

\section{Experimental details}

$\mathrm{Ag}-\mathrm{Cu}$ alloy NPs were prepared through a two-step process: (a) laser ablation and (b) laser irradiation. A schematic of the Ag,
$\mathrm{Cu}$ and $\mathrm{Ag}-\mathrm{Cu}$ alloy NPs fabrication by laser ablation (left) and laser irradiation of colloidal mixture (right) is presented in Fig. 1. In the first step, $\mathrm{Ag}$ and $\mathrm{Cu}$ NPs were obtained individually by laser ablation in liquid (LAL) technique. In the second step the previously prepared NPs equal volume were mixed and irradiated as discussed below.

\section{Synthesis of monometallic $\mathrm{Ag}$ and $\mathrm{Cu}$ NPs}

$\mathrm{Ag}$ and $\mathrm{Cu}$ NPs were produced separately by laser ablation of $\mathrm{Ag} /$ $\mathrm{Cu}$ target immersed in distilled water (DW) using a femtosecond (fs) amplifier system (Libra, M/s Coherent, USA) operating at a central wavelength of $800 \mathrm{~nm}$ with a pulse duration $\sim 50 \mathrm{fs}$ at a pulse frequency of $1 \mathrm{kHz}$. The laser beam was focused vertically through the plano-convex lens $(f=10 \mathrm{~cm})$ on to the $\mathrm{Ag} / \mathrm{Cu}$ target of $\sim 1 \mathrm{~mm}$ thick (purity $>99.9 \%$, purchased from Sigma Aldrich) placed at the bottom of the glass cell containing $10 \mathrm{~mL}$ of distilled water (DW) and the covered liquid layer was $\sim 11 \mathrm{~mm}$ from the target surface. The focal point on the target was monitored and optimized by observing the generated bright light (from the plasma) and listening to the crackling sound resulting from ablation. To avoid repeated ablation of a single spot on the target as well as to increase the NPs productivity, the sample was translated using a computer controlled translational stage. A speed of $0.1 \mathrm{~mm} \mathrm{~s}^{-1}$ was used along the $X$ and $Y$ directions. The experiments were performed at a pulse energy of $300 \mu \mathrm{J}$ and the corresponding laser fluence was $\sim 3.8 \mathrm{~J} \mathrm{~cm}^{-2}$. The ablation time was typically 30 minutes in both the cases ( $\mathrm{Ag} / \mathrm{Cu}$ ablation). Briefly, in the ablation process, high temperature and higher pressured plasma are formed at the target-liquid interface when it interacts with the intense laser pulse. The produced plasma plume comprises various ablated species such as atoms, molecules, ions, electrons, cluster, etc. During the continuous ejection of plasma, a shock wave is generated and is quenched into the surrounding liquid after some time resulting in the cavitation bubble. After few $\mu \mathrm{s}$, the continuous growth of cavitation bubble ends up and collapses. Under suitable conditions the plasma species will nucleate and growth into the NPs in liquid..$^{11,12,31,32}$

\section{Synthesis of Ag-Cu alloy NPs}

To synthesise the Ag-Cu alloy NPs, previously prepared $\mathrm{Ag}$ and $\mathrm{Cu}$ colloidal solutions were mixed in equal volumes $(2.5 \mathrm{~mL}$ each) and then irradiated with an unfocused laser $(800 \mathrm{~nm})$ beam with a pulse energy of $150 \mu \mathrm{J}$ and the corresponding laser fluence per pulse $\sim 0.2 \mathrm{~mJ} \mathrm{~cm}{ }^{-2}$. The colloidal solution was continuously stirred with the help of magnetic stirrer $(50 \mathrm{rpm})$ to expedite the movement of particles and to avoid gravitational settling of the NPs. To maintain homogenous irradiation process and to interact with large number of NPs a quite large ( $\sim 10 \mathrm{~mm}$, without focusing) laser spot was used. The laser irradiation time was varied as 15, 30, 60 and 90 minutes and the colloidal mixture was studied by recording the absorption spectra at each step. The irradiation which lasted for 90 minutes demonstrated single SPR peak under these experimental conditions. 


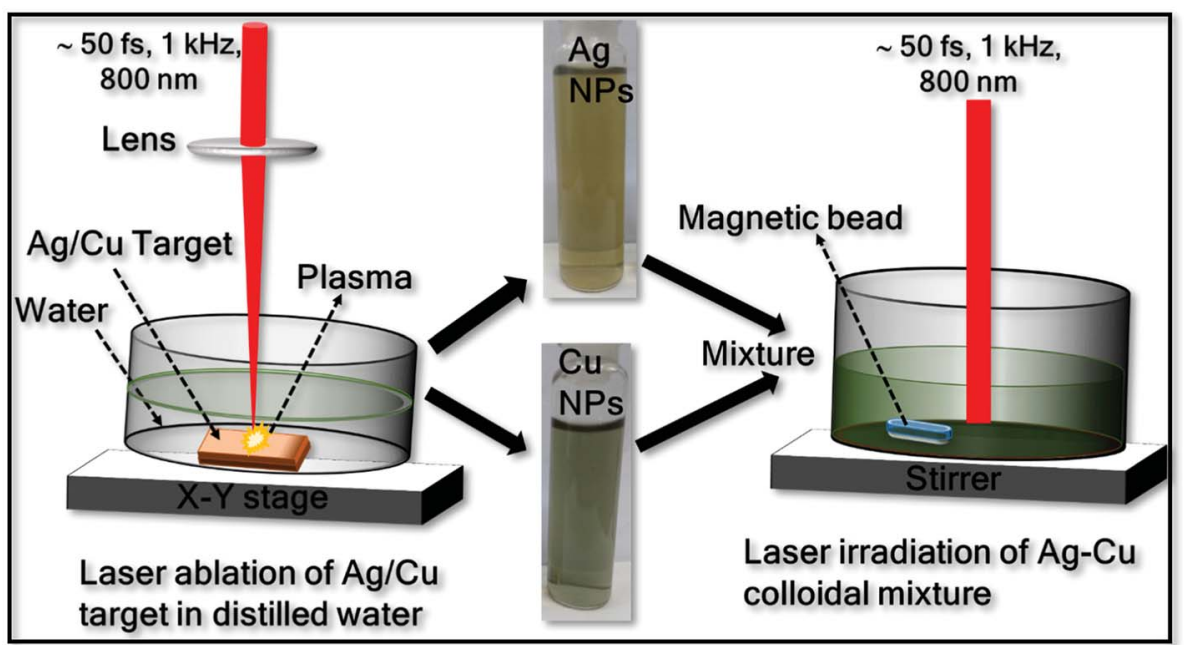

Fig. 1 Schematic representation of the synthesis of Ag-Cu alloy NPs (laser ablation and irradiation), the inset shows the photographs of pure Ag and Cu NPs.

The Ag, $\mathrm{Cu}$ and $\mathrm{Ag}-\mathrm{Cu}$ alloy NPs were characterised by UVvisible absorption (PerkinElmer Lambda 750) spectrometer. The fabricated NPs size, shape and crystallinity were confirmed from the high resolution transmission electron microscopy (HRTEM, operated with $200 \mathrm{kV}$ ) data. Additionally, elemental mapping and EDX measurements for $\mathrm{Ag}-\mathrm{Cu}$ NPs were conducted using a field emission scanning electron microscope (FESEM) (Carl Zeiss model Merlin compact 6027) operated with a beam voltage of $30 \mathrm{kV}$. For further characterization of composition of the prepared NPs, X-ray diffraction (XRD) patterns were recorded using a powder X-ray diffractometer (Discover D8 diffractometer of Bruker, Germany) with $\mathrm{Cu} \mathrm{K} \alpha$ radiation $(\lambda=0.15408 \mathrm{~nm})$. The fabricated NPs were dried (drop by drop) on cleaned Si wafer for the XRD sample preparation. For SERS substrate preparation, the obtained NPs $(20 \mu \mathrm{L})$ were drop-casted on cleaned silicon ( $\mathrm{Si}$ ) substrates and dried on a hotplate at $40^{\circ} \mathrm{C}$. The probe molecules of 2,4,6-trinitrophenol (picric acid, PA), ammonium nitrate (AN) and methylene blue (MB) were prepared in stock solutions and subsequently diluted for achieving lower concentrations. A tiny amount $(\sim 20 \mu \mathrm{L})$ of the analyte molecule was dropped over the dried NPs film on Si. The Raman spectra were acquired by utilising a 50X (Numerical Aperture of 0.55) objective lens to focus the $632 \mathrm{~nm}$ (Micro Raman, HORIBA) excitation source on to sample and we used an integration time of $5 \mathrm{~s}$. The used laser power for Raman measurements was $\sim 2 \mathrm{~mW}$ and the estimated spot size on the samples was $\sim 1.4 \mu \mathrm{m}$. The EFs were estimated using the relation $\mathrm{EF}=\left(I_{\mathrm{SERS}} \times C_{\mathrm{R}}\right) /\left(I_{\mathrm{R}} \times C_{\text {SERS }}\right)$, where $I_{\text {SERS }}$ is the Raman signal intensity in the presence of NPs, $I_{\mathrm{R}}$ is the Raman intensity in the absence of NPs, $C_{\mathrm{SERS}}$ is the concentration of sample on NP substrates (low concentration), and $C_{\mathrm{R}}$ is the concentration $(0.1 \mathrm{M})$ of sample on bare $\mathrm{Si}$, which produces the Raman signal $\left(I_{\mathrm{R}}\right)$. Lower concentrations of analyte molecules $\left(10^{-3}\right.$ to $\left.10^{-9} \mathrm{M}\right)$ were prepared by further dilution of the stock solution $0.1 \mathrm{M}$. The higher concentration Raman spectra of MB, PA and AN (0.1 M) were also recorded for comparison purpose.

\section{Results and discussion}

\section{UV-visible absorption studies}

Fig. 2 illustrates the UV-visible absorption spectra of fs laserablated $\mathrm{Ag}, \mathrm{Cu}$ NPs and laser irradiated $\mathrm{Ag}-\mathrm{Cu}$ alloy NPs (after $90 \mathrm{~min}$ ). The surface plasmon resonance (SPR) peak in the UVvisible absorption spectra of the synthesised colloidal solutions confirms the presence of the NPs. The SPR peak of Ag NPs, Cu NPs were located at $408 \mathrm{~nm}, 616 \mathrm{~nm}$, respectively, indicating that the obtained NPs were in almost spherical shape. The SPR peak of irradiated $\mathrm{Ag}$ and $\mathrm{Cu}$ colloidal mixture for 90 minutes was appeared at $\sim 554 \mathrm{~nm}$ which is in between the individual SPR peaks of pure Ag and pure Cu NPs.

In the case of mixture of $\mathrm{Ag}$ and $\mathrm{Cu}$ NPs before laser irradiation, two separate SPR peaks, corresponding to Ag and Cu NPs, were observed which implies the absence of formation of alloy NPs. Similar was the case even after irradiating the colloidal mixture even after 15 minutes. Upon further increasing the irradiation time the SPR peak corresponding to pure Ag NPs has

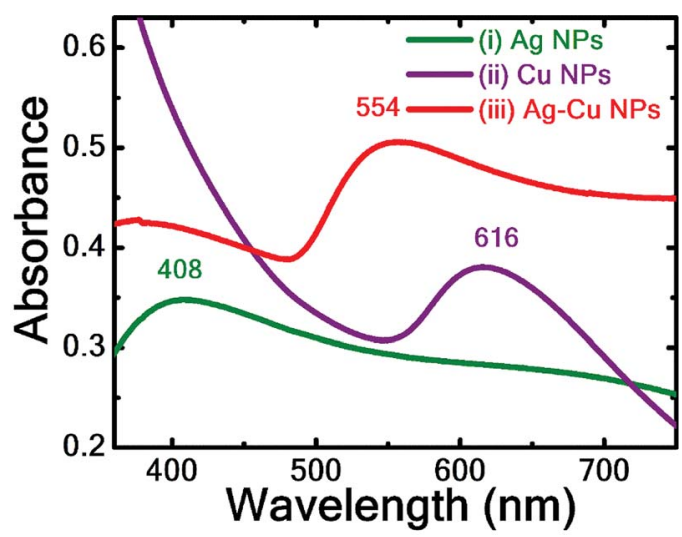

Fig. 2 UV-visible absorption spectra of $\mathrm{Ag}, \mathrm{Cu}$ and $\mathrm{Ag}-\mathrm{Cu}$ NPs with $\lambda_{\max } 408,616$ and $554 \mathrm{~nm}$ respectively. 
undergone a red shift i.e. from $408 \mathrm{~nm}$ to $413 \mathrm{~nm}$ (30 minutes) and to $417 \mathrm{~nm}$ (60 minutes) and the absorption band intensity has increased sharply. This could be attributed to the possible fragmentation of larger size NPs into smaller NPs during the laser irradiation process which may lead to the increase of absorption band intensity. The reduction in size of NPs is also revealed form TEM image analysis [data presented in Fig. 3]. Pure $\mathrm{Ag}$ and $\mathrm{Cu}$ NPs size distribution was up to $\sim 100 \mathrm{~nm}$ while the irradiated $\mathrm{Ag}-\mathrm{Cu}$ alloy NPs size distribution was up to $\sim 50 \mathrm{~nm}$. However, there was only a small change in the average size of NPs. A quick decrease in intensity of $\mathrm{Cu}$ NPs SPR peak after prolonged irradiation (30-90 $\mathrm{min}$ ) could be ascertained to the larger absorption cross-section of $\mathrm{Cu}$ NPs (in comparison to $\mathrm{Ag}$ NPs) at $800 \mathrm{~nm}$ as observed by Ghaforyan et $a l .{ }^{33}$ and also the melting temperature of metal NPs decreases with the size of the NPs (average size of $\mathrm{Cu}$ NPs < average size of NPs). However, to arrive at the complete understanding of variation in absorption band intensities of irradiated NPs, further investigations are warranted. We highlighted the observed small hump in the 500-600 nm spectral regions with yellow colour to clearly depict the hump (shown in Fig. S1 of the ESI $\dagger$ ). While increasing the irradiation time the absence of two plasmon peaks and the presence of a single SPR peak confirmed the spherical formation of $\mathrm{Ag}-\mathrm{Cu}$ alloy NPs rather than a mixture of two individual metal NPs. ${ }^{34-36}$ There are several reports from various researchers discussing the various factors involved in tuning of
SPR peak in the alloy NP formation with respect to the composition of the constituent materials. Jiang et al. synthesised $\mathrm{Ag}-\mathrm{Cu}$ alloy NPs by the polyol process and observed the single SPR peak at $554 \mathrm{~nm}$ for $1: 1$ volume ratio of pure $\mathrm{Ag}$ and $\mathrm{Cu}$ NPs. ${ }^{37}$ Messina et al. also demonstrated the tuning of $\mathrm{Au}_{x^{-}}$ $\mathrm{Ni}_{1-x}$ alloy NPs composition upon laser irradiation of colloidal mixture with different ratios. ${ }^{17}$ Valodkar et al. synthesised $\mathrm{Ag}-$ $\mathrm{Cu}$ alloy NPs with a green approach and observed the red shift in plasmon band from 416 to $584 \mathrm{~nm}$ with an increase of $\mathrm{Cu}$ content in $\mathrm{Ag}-\mathrm{Cu}$ alloy NPs. ${ }^{38}$ Compagnian et al. ${ }^{39}$ recently reported the synthesis of $\mathrm{Au} / \mathrm{Ag}$ colloidal nanoalloys by laser ablation and irradiation and observed the rise in absorption band intensity with increasing irradiation time. Peng et al. ${ }^{\mathbf{4 0}}$ synthesized $\mathrm{Au}-\mathrm{Ag}$ nanoalloys by laser irradiation of mixed colloids (Ag and $\mathrm{Au}$ ) and noticed the changes in SPR band intensities of $\mathrm{Ag}$ and $\mathrm{Au}$ NPs while irradiating the mixed colloidal solution. The observed changes were attributed to the lower melting point of Ag NPs than the Au NPs.

\section{TEM analysis of colloidal NPs}

Fig. 3 illustrates the TEM micrographs of synthesised Ag, Cu and $\mathrm{Ag}-\mathrm{Cu}$ alloy NPs. Fig. 3(a)-(c) depict the morphology and their insets shows their respective size distribution histograms of $\mathrm{Ag}, \mathrm{Cu}$ and $\mathrm{Ag}-\mathrm{Cu} \mathrm{NPs}$, respectively. There are no noticeable morphological changes observed for $\mathrm{Ag}-\mathrm{Cu}$ NPs after laser irradiation. Most of the NPs were found to be spherical with the

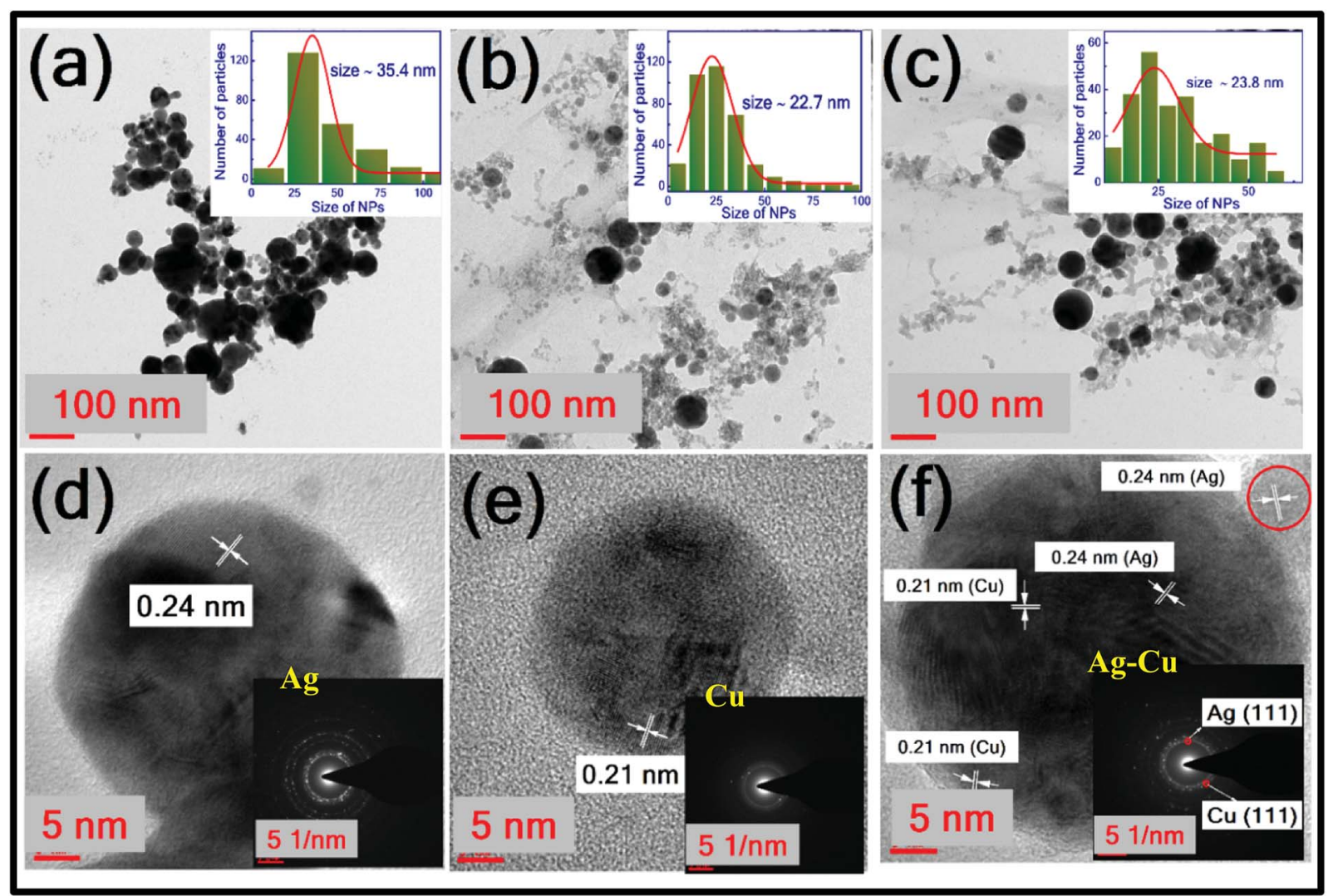

Fig. 3 TEM and HRTEM images of ( $a$ and $d$ ) Ag NPs ( $b$ and e) Cu NPs ( $c$ and f) Ag-Cu NPs. Insets of $(a-c)$ and (d-f) depict their size distribution and SAED patterns, respectively. 
average diameter of $\sim 35.4 \mathrm{~nm}, \sim 22.7 \mathrm{~nm}$, and $\sim 23.8 \mathrm{~nm}$, corresponding to the $\mathrm{Ag}, \mathrm{Cu}$, and $\mathrm{Ag}-\mathrm{Cu}$ NPs. Fig. 3(d)-(f) depict the HRTEM images of $\mathrm{Ag}, \mathrm{Cu}, \mathrm{Ag}-\mathrm{Cu}$ alloy NPs and the insets illustrate their selected area electron diffraction (SAED) patterns. Both elements have the same face-centred cubic structure $^{\mathbf{4 1 , 4 2}}$ differing only in the lattice parameters. The lattice fringe spacing of $0.24 \mathrm{~nm}$ confirmed the $d$-spacing of $\mathrm{Ag}$ (111) plane and the value of $0.21 \mathrm{~nm}$ corresponds to the $\mathrm{Cu}$ (111) plane. The presence of two inter-planar spacing in the HRTEM image of $\mathrm{Ag}-\mathrm{Cu}$ alloy NPs [0.24 nm and $0.21 \mathrm{~nm}$ corresponding to $\mathrm{Ag}$ and $\mathrm{Cu}$ ] confirms the formation of alloy NPs. ${ }^{43}$ Likewise, the SAED pattern shown in the inset of Fig. 3(f) reveals the presence of $\mathrm{Ag}$ and $\mathrm{Cu}$ constituents in the alloy NPs. Boyer et al. synthesised Co-Au nanoclusters by laser irradiation of a mixed Co and Au colloids and their characterisation studies confirmed the each NP is composed of both atoms. ${ }^{44}$ Petrovic et al. generated $\mathrm{Cu}-\mathrm{Ag}$ NPs by the ablation of $\mathrm{Cu}$ target in $\mathrm{Ag}$ colloidal solution. ${ }^{45}$ Aazadfar et al. have also recently demonstrated the synthesis of $\mathrm{Au} / \mathrm{Copper}$ oxide nanocomposites by the irradiation of individually prepared $\mathrm{Au}$ and copper oxide colloidal mixture. ${ }^{46}$

\section{FESEM analysis}

Fig. 4(a)-(f) depict the elemental mapping of typical Ag-Cu alloy NPs (after $90 \mathrm{~min}$ ) by FESEM which further confirms the formation of alloy NPs upon laser irradiation of mixed colloidal solution. The overall elemental distribution in Ag-Cu alloy NPs is depicted from Fig. 4(a), distribution of $\mathrm{Ag}$ (green colour) in Fig. 4(c) and distribution of $\mathrm{Cu}$ (red colour) in Fig. 4(b). The line map of $\mathrm{Ag}$ and $\mathrm{Cu}$ elements on single particle as shown in
Fig. 4(d) and (e) divulge the single NP composed of Ag rich centre. The energy dispersive X-ray spectrum shows the presence of $\mathrm{Ag}$ (atomic 55\%) and $\mathrm{Cu}$ (atomic 45\%) atoms. While some NPs are Cu-rich (as seen in Fig. 4(a)) we believe that the alloy composition will be slightly different for different NPs because of irradiation effects, which could be non-uniform. Generally when an unfocused laser beam is utilized to irradiate the colloidal mixture it avoids the formation of different electron temperatures in the vicinity of different particles. With the unfocused laser irradiation the temperature conditions at nanocolloids are similar and homogeneous. Recently proposed photothermal evaporation model (heating-melting-evaporation) clarified the particle interaction with the laser at different phase transitions of material. ${ }^{\mathbf{7}}$

In the process of irradiation, the absorption of laser pulse energy depends on several factors such as size, shape and absorption cross section of NPs and also the input laser fluence. The absorption results in the particle heating and, therefore, the temperature of the $\mathrm{Ag} / \mathrm{Cu}$ NPs dispersed in the solvent will rise dramatically up to the melting point. Subsequently, the heat loss possibly leads to the particle cooling and also particle solidification. The conceivable solidification could happen in the time scale of $10^{-5}$ to $10^{-6} \mathrm{~s}$, which is much higher than the input pulse duration (fs). Through repeated multi-pulse interaction, laser energy absorption and melting-solidification of the NPs could occur. During each short period, diffusion of different chemical species $\mathrm{Ag} / \mathrm{Cu}$ NPs in the melt pool, the coalescence between the $\mathrm{Ag}$ and $\mathrm{Cu}$ atoms may perhaps happen leading to the formation of $\mathrm{Ag}-\mathrm{Cu}$ alloy NPs. The homogenization of the alloy NPs and enhanced diffusion are improved by

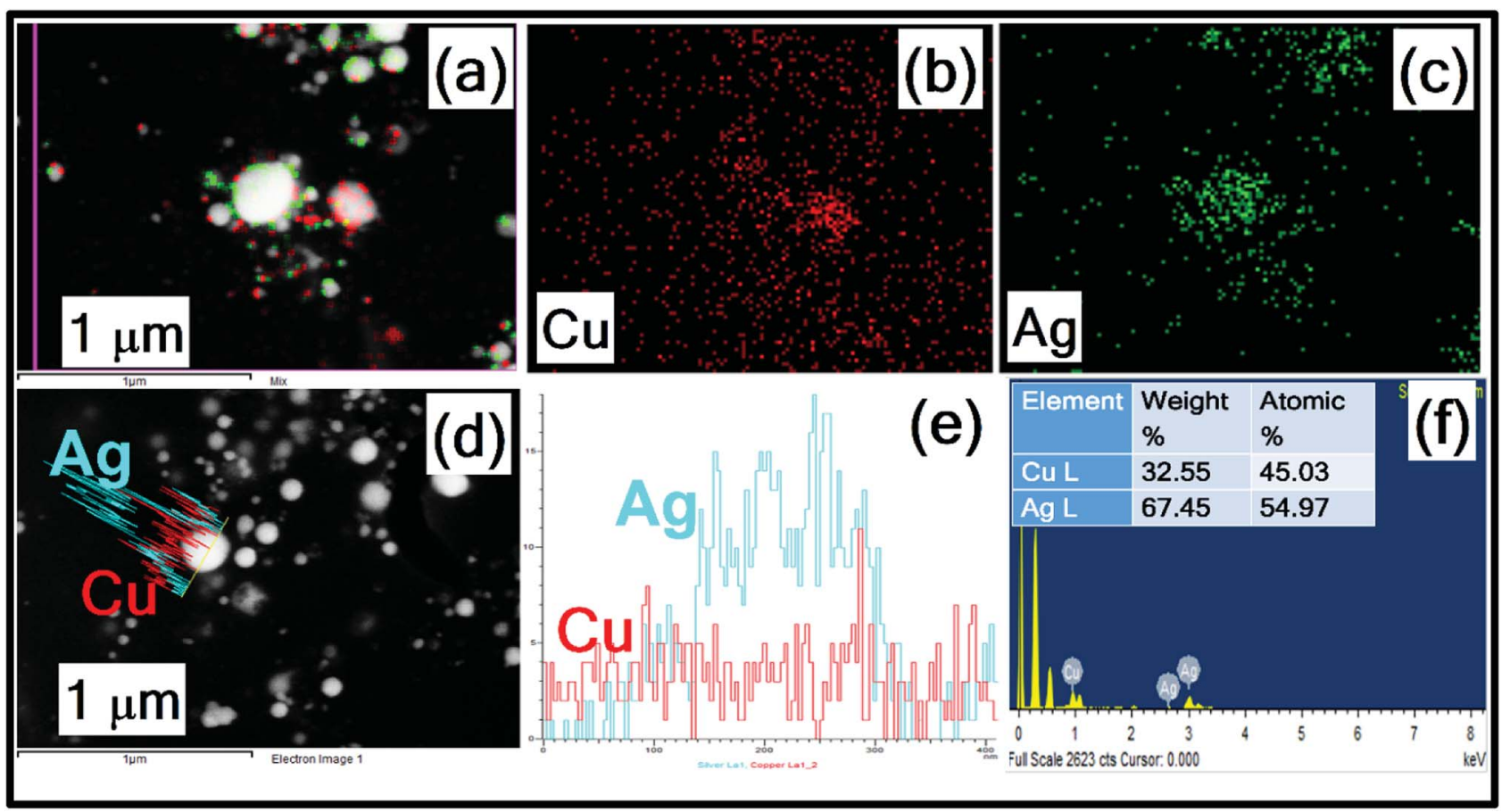

Fig. 4 FESEM - EDS mapping of $(a-c) A g-C u$ alloy NPs (d) line profile of single particle (e) intensity distribution (f) EDS spectra with an inset depicting the wt\% of individual elements. 
three forces of gravity, viscosity and strength due to surface tension gradients. ${ }^{48}$ The morphology transitions of $\mathrm{Ag}-\mathrm{Cu}$ alloy NPs as a function of $\mathrm{Ag} / \mathrm{Cu}$ concentration needs further detailed studies which can achieved by varying the volume ratios of $\mathrm{Ag}$ and $\mathrm{Cu}$ NPs.

The XRD patterns of the Ag-Cu alloy NPs and individual NPs $(\mathrm{Ag}, \mathrm{Cu})$ drop casted on $\mathrm{Si}$ are shown in Fig. S2 (of ESI†). The analysis of X-ray diffraction results indicates formation of two types of phases in $\mathrm{Ag}-\mathrm{Cu}$ alloy NPs corresponding to both $\mathrm{Ag}$ and $\mathrm{Cu}$. The XRD spectra of $\mathrm{Ag}-\mathrm{Cu}$ alloy NPs with the two peaks observed are attributed to the Ag planes (111) and (200) [JCPDS file number Ag-04-0783] and the other two peaks correspond to $\mathrm{Cu}$ planes (111) and (200) [JCPDS file number $\mathrm{Cu}-85-1326$ ]. A small shift in the peak locations was observed when compared to pure NPs, which could be due to the complex alloy formation. ${ }^{49}$ The peak located at $28.6^{\circ}$ corresponds to Si. The present results obtained are similar to those of Malviya et al., ${ }^{50}$ who recently analysed the X-ray diffraction results of $\mathrm{Ag}-\mathrm{Cu}$ alloy NPs of four different compositions of two types of phases, Ag and $\mathrm{Cu}$ rich solid solution. ${ }^{50}$ To understand the minor XRD peak shifts and broadening with respect to the composition of NPs, further investigations are warranted.

\section{SERS activity of $\mathrm{Ag}, \mathrm{Cu}$ and $\mathrm{Ag}-\mathrm{Cu} \mathrm{NPs}$}

The SERS performance of laser fabricated NPs (Ag, Cu and Ag$\mathrm{Cu}$ NPs) was investigated by choosing MB as a probe molecule. The corresponding spectra is shown in Fig. 5. Here, SERS activity of the bimetallic Ag-Cu NPs was tested and compared with the pure $\mathrm{Ag}$ and $\mathrm{Cu}$ NPs using laser excitation of $632 \mathrm{~nm}$. The MB ( $5 \mu \mathrm{M})$ SERS spectra obtained from $\mathrm{Ag}, \mathrm{Cu}$ and $\mathrm{Ag}-\mathrm{Cu}$ alloy NPs as depicted in Fig. 5 and the observed modes well matched to the earlier reports. ${ }^{14,30,51,52}$ The ring stretching mode of MB (1621 $\left.\mathrm{cm}^{-1}\right)$ was elected to calculate the SERS efficiency. The obtained EFs for $\mathrm{Ag}$, $\mathrm{Cu}$ and $\mathrm{Ag}-\mathrm{Cu}$ NPs were $5.5 \times 10^{3}, 7.5$ $\times 10^{2}$ and $7.2 \times 10^{3}$, respectively, and the comparison histogram is shown in Fig. S3. $\dagger$ The lower SERS signals were exhibited by the Cu NPs, because of its lesser SERS cross section compared to Ag. For Ag-Cu alloy NPs 1.3 times higher EFs was noticed than the Ag NPs, could be ascribed to the

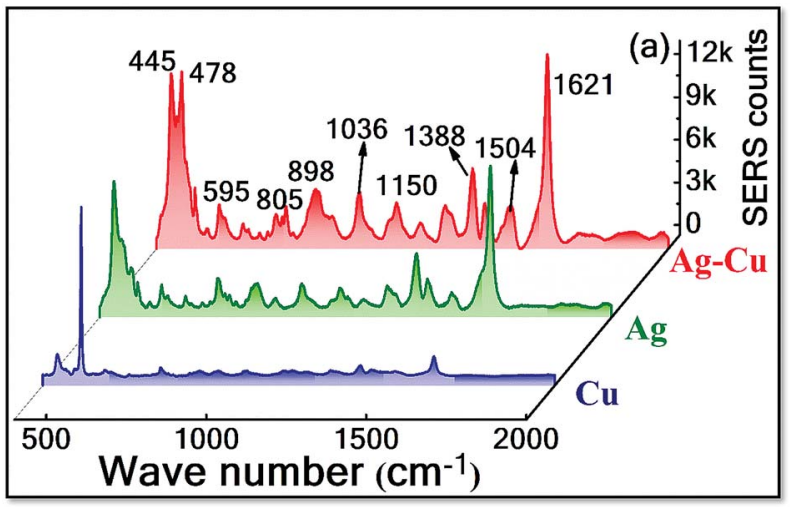

Fig. 5 SERS spectra of MB achieved using $\mathrm{Ag}, \mathrm{Cu}$ and $\mathrm{Ag}-\mathrm{Cu}$ alloy NPs. electromagnetic coupling at the interface of $\mathrm{Cu}$ and $\mathrm{Ag}$, which generates the superior localised EM field and synergetic effect. ${ }^{8,53} \mathrm{He}$ et al. fabricated $\mathrm{Ag}-\mathrm{Cu}$ alloy NPs by galvanic replacement technique and shown the tailorable SERS and catalysis activity. ${ }^{54} \mathrm{Hu}$ et al. reported the $\mathrm{Ag}-\mathrm{Cu}$ SERS substrate act as a promising material for detection R6G $\left(10^{-13} \mathrm{M}\right){ }^{55}$

The detection sensitivity of $\mathrm{Ag}-\mathrm{Cu}$ NPs was examined by collecting the MB SERS spectra with varied concentrations (from $0.5 \mathrm{mM}$ to $5 \mathrm{nM}$ ) and the data shown in Fig. 6(a). A good correlation observed between the $1621 \mathrm{~cm}^{-1}$ peak intensity and the MB concentrations $\left(5 \times 10^{-4}\right.$ to $\left.5 \times 10^{-9} \mathrm{M}\right)$. Fig. 6 (b) shows the plot where $Y$-axis corresponds to the $1621 \mathrm{~cm}^{-1}$ peak intensity and $X$-axis corresponds to the molecule concentration (in $\log$ scale), and the retrieved $R^{2}$ value was found to be $\sim 0.98$. The obtained EF for $\mathrm{MB}(5 \mathrm{nM})$ was $\sim 3 \times 10^{7}$. To further investigate SERS capability of these $\mathrm{Ag}-\mathrm{Cu}$ alloy NPs in the detection of different explosives molecules. The probe molecules of PA and AN were considered to investigate the SERS performance. PA is a well-known explosive molecule and synthesized from freely available chemicals while AN is a commonly used fertilizer and often used in high energy materials. In recent years explosive sensing has renewed interested because of the dramatically increasing anti-national and anti-social activities. SERS has the potential to provide the detection of explosive due to its sensitivity and molecular finger printing ability. ${ }^{56}$ Podagatlapalli et al. achieved detection of $5 \times$ $10^{-6} \mathrm{M}$ (ANTA), ${ }^{57} 10^{-6} \mathrm{M}$ (FOX-7) ${ }^{58}$ by $\mathrm{Ag}$ laser ablation nanocavities. Hamad et al. ${ }^{59}$ detected $10^{-6} \mathrm{M}$ (CL-20) by using laser ablated $\mathrm{Cu}$ NS. Zhang et al. detected $10^{-6} \mathrm{M}$ of TNT by using Au NPs. ${ }^{60}$ Holthoff et al. detected $3 \times 10^{-6} \mathrm{M}$ of TNT by using commercially available Klarite ${ }^{\mathrm{TM}}$ MIPS substrate. ${ }^{\mathbf{6 1}}$ Sajanlal et al. detected $10^{-7} \mathrm{M}$ (DNT) and $10^{-6} \mathrm{M}$ (RDX) by using Ni/Au nanocarpets. ${ }^{62}$ Hatab et al. were able to detect $7 \times 10^{-6} \mathrm{M}$ (TNT) by using Au nano bowtie. ${ }^{63}$ The SERS spectra of PA were recoded for different concentrations ranging from $5 \times 10^{-3}$ to $5 \times$ $10^{-6} \mathrm{M}$ and the data are shown in Fig. 6(c). All the observed Raman peaks at 709, 827, 937, 947, 1163, 1315, 1348 and $1373 \mathrm{~cm}^{-1}$ matched well with some of the earlier reports. ${ }^{51,64}$

The three major characteristic modes at 827, 1315 and $1348 \mathrm{~cm}^{-1}$ were identified even at a concentration of $5 \mu \mathrm{M}$. The enhancement factor (EF) was estimated using the $827 \mathrm{~cm}^{-1}$ peak of PA $(5 \mu \mathrm{M})$ and it was found to be $\sim 2.8 \times 10^{4}$. Fig. $6(\mathrm{~d})$ represents the log-log plot which exhibited a linear relationship with an $R^{2}$ value of 0.91 for PA for the prominent peak of $827 \mathrm{~cm}^{-1}$. Similarly, the SERS spectra of AN was obtained for different concentrations ranging from $5 \times 10^{-3}$ to $5 \times 10^{-6} \mathrm{M}$ and the data is shown in Fig. 6(e). All the observed Raman peaks at 712,1047 and $1362 \mathrm{~cm}^{-1}$ are well-matched with reported data from literature. ${ }^{65,66}$ The peaks assignments are summarized in Table S1. $\dagger$ The main characteristic peak of $1047 \mathrm{~cm}^{-1}$ is assigned to $\mathrm{NO}_{3}{ }^{-}$stretch mode and the estimated EF for AN (5 $\mu \mathrm{M}$ ) was $\sim 3.3 \times 10^{4}$. Fig. $6(\mathrm{f})$ represents the log-log plot which clearly suggests a linear relationship with an $R^{2}$ value of 0.9 for AN. The maximum EF was observed for $\mathrm{MB}$ compared to explosive molecule possibly because of the coupling between the excitation wavelength and an electronic transition of the target molecule (MB). The Raman cross-section of MB molecule 


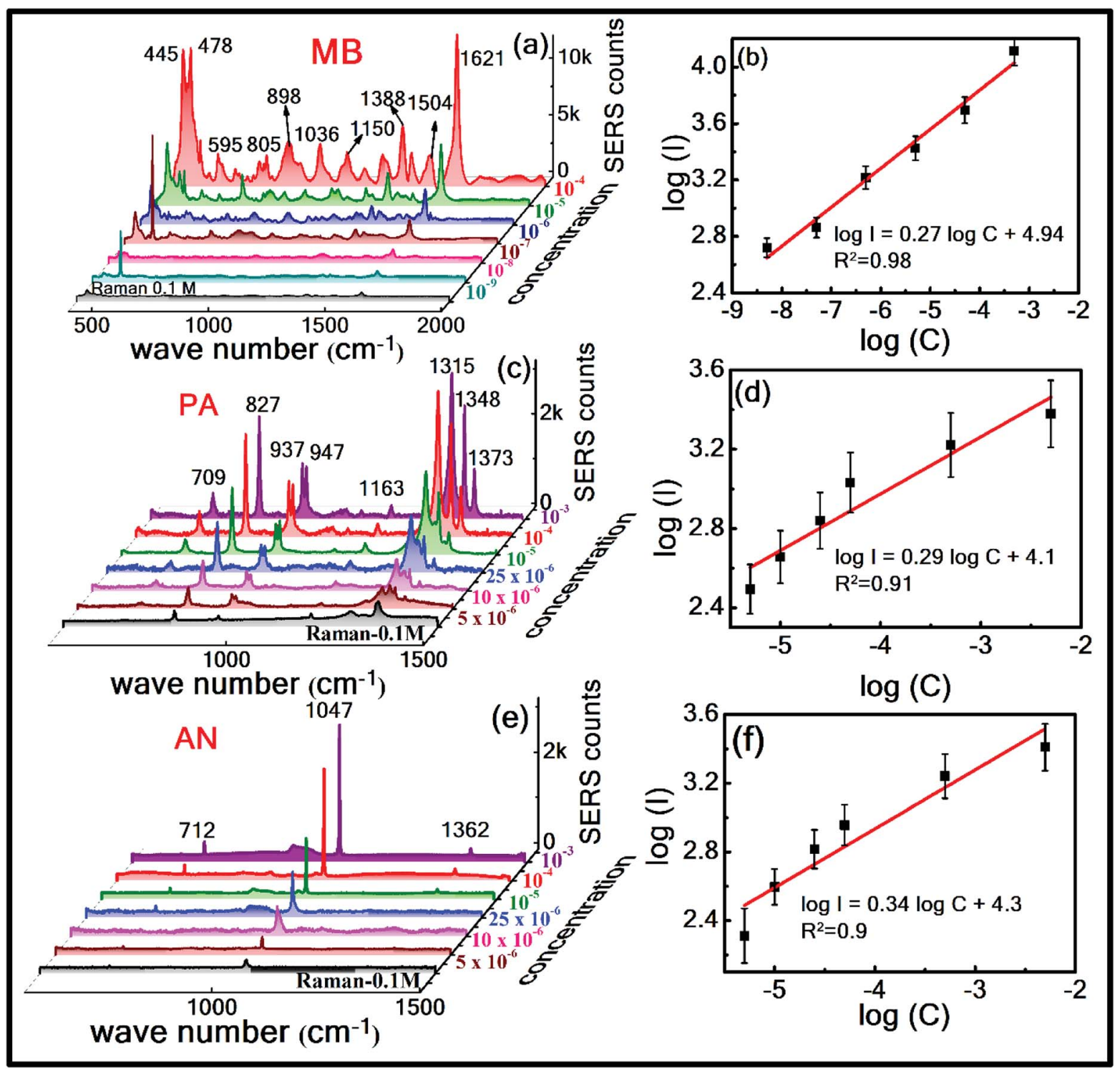

Fig. 6 Concentration dependent SERS spectra of (a) MB with concentrations ranging from $5 \times 10^{-4}$ to $5 \times 10^{-9} \mathrm{M}$ (c) PA ranging from $5 \times 10^{-3}$ to $5 \times 10^{-6} \mathrm{M}$ (e) AN ranging from $5 \times 10^{-3}$ to $5 \times 10^{-6} \mathrm{M}$ and SERS intensity at (b) $1621 \mathrm{~cm}^{-1}$ peak intensity versus MB concentration (d) $827 \mathrm{~cm}^{-1}$ peak intensity versus PA concentration (f) $1047 \mathrm{~cm}^{-1}$ peak intensity versus AN concentration using Ag Cu alloy NPs. Black spectra in (a), (c), and (e) represent the 0.1 M concentration Raman spectra of the corresponding molecule. In the curves (b), (d) and (f) black squares represent the experimental data while the red lines represent theoretical fits.

is higher and, therefore, we achieved good signals when we performed SERS measurements on this molecule. And also the probe molecule $\mathrm{MB}$ has the absorption maxima located at $\sim 653 \mathrm{~nm}$ and the Raman excitation source was $632.8 \mathrm{~nm}$.

The reproducibility of SERS substrate is a critical parameter for determining their applications in practical and real-world situations. Here, we have examined the reproducibility of the $\mathrm{Ag}$ - $\mathrm{Cu}$ NPs substrate using the same molecules as mentioned above. For each molecule the SERS spectra were recorded form 10 randomly selected spots on $\mathrm{Ag}-\mathrm{Cu}$ alloy NPs substrate and the measured relative standard deviation (RSD) values for $\mathrm{MB}$ $\left(1621 \mathrm{~cm}^{-1}\right)$, PA $\left(827 \mathrm{~cm}^{-1}\right)$ and AN $\left(1047 \mathrm{~cm}^{-1}\right)$ were $\sim 7.08 \%$, $8.58 \%$, and $8.08 \%$, respectively. Fig. 7 shows the histogram plot for the peak intensity of the highly elevated mode in each molecule relative to the spot number, which demonstrates the excellent homogeneity of the SERS substrate even in various analyte molecules identification. The plotted 3D SERS spectra by considering the Raman signals at 10 different sites on $\mathrm{Ag}-\mathrm{Cu}$ alloy NPs substrate provided in the S4-S6 (MB-S4; PA-S5; AN$\mathrm{S} 6 \dagger)$. By comparing the performance of various alloy NPs from recently reported reports ${ }^{57-63} \mathrm{Ag}-\mathrm{Cu}$ NPs as SERS substrates have undoubtedly demonstrated comparable/superior SERS performance. Further improvements are possible in the enhancement factors by combining the NPs and the NSs together (as we have demonstrated it recently). ${ }^{\mathbf{1 4}}$ Further optimization studies on various ratios of these metals and different laser irradiation times are possible for preparing even efficient SERS substrates. Addition of $\mathrm{Cu}$ will not only reduce the cost of 


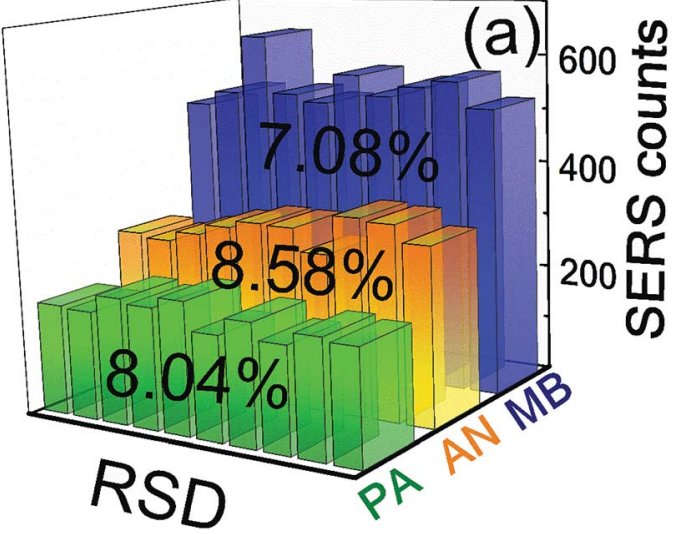

Fig. 7 Reproducibility of the SERS intensities for significant modes of MB ( $5 \mathrm{nM}$ - blue colour), PA ( $5 \mu \mathrm{M}$ - green colour) and AN (5 $\mu \mathrm{M}-$ orange colour) recorded at 10 different spots on Ag-Cu NPs SERS substrate. The watermark shows the estimated RSD values.

these substrates but could also improve the stability. Further research is necessary to identify the benefits of individual metal NPs, bi-metallic and tri-metallic NPs to arrive at efficient SERS substrates.

\section{Conclusions}

The following are the conclusions from the present detailed study:

- Ag-Cu alloy NPs were fabricated using two consecutive steps of laser ablation and irradiation.

- The observed the single SPR peak from the UV-visible absorption spectra of $\mathrm{Ag}-\mathrm{Cu}$ alloy NPs lies in between pure NPs, indicates the formation of alloy NPs.

- XRD, TEM and FESEM-EDX mapping analysis revealed that the alloy NPs are composed of both $\mathrm{Ag}$ and $\mathrm{Cu}$ atoms with composition of $54 \%$ and $46 \%$, respectively, obtained from the EDX data.

- The SERS performance of these NPs was investigated for a dye molecule of MB and we conclude that the composite NPs exhibit superior SERS signals compared to pure NPs ( $\mathrm{Ag}$ or $\mathrm{Cu}$ ).

- $\mathrm{Ag}-\mathrm{Cu}$ alloy NPs also served as active SERS substrates towards quantitative detection of common explosives such as picric acid and ammonium nitrate at low concentrations.

- These NPs as SERS substrates demonstrated greater reproducibility with reasonable RSD values.

\section{Conflicts of interest}

There are no conflicts to declare.

\section{Acknowledgements}

The authors thank DRDO, India for continuous financial support. The authors also thank Mr Ravi Kiran Gadde, School of Engineering Sciences \& Technology, University of Hyderabad for help in XRD characterization. Authors also thank Centre for
Nanotechnology, University of Hyderabad for extending the TEM facility.

\section{References}

1 K. Chen, X. Zhang, Y. Zhang, D. Y. Lei, H. Li, T. Williams and D. R. MacFarlane, Adv. Mater. Interfaces, 2016, 3, 1600115.

2 Y. Tao, M. Li, J. Ren and X. Qu, Chem. Soc. Rev., 2015, 44, 8636-8663.

3 Y. Wei, Y. Y. Zhu and M. L. Wang, Optik, 2016, 127, 1073510739.

4 A. Guerrero-Martínez, S. Barbosa, I. Pastoriza-Santos and L. M. Liz-Marzán, Curr. Opin. Colloid Interface Sci., 2011, 16, 118-127.

5 J. Zhang, M. Chaker and D. Ma, J. Colloid Interface Sci., 2017, 489, 138-149.

6 S. H. Stelzig, C. Menneking, M. S. Hoffmann, K. Eisele, S. Barcikowski, M. Klapper and K. Müllen, Eur. Polym. J., 2011, 47, 662-667.

7 K. S. Tan and K. Y. Cheong, J. Nanopart. Res., 2013, 15, 1537. 8 D. Li, J. Liu, H. Wang, C. J. Barrow and W. Yang, Chem. Commun., 2016, 52, 10968-10971.

9 B. Tsaur, S. Lau and J. Mayer, Appl. Phys. Lett., 1980, 36, 823826.

10 S. V. Rao, G. K. Podagatlapalli and S. Hamad, J. Nanosci. Nanotechnol., 2014, 14, 1364-1388.

11 V. Amendola and M. Meneghetti, Phys. Chem. Chem. Phys., 2009, 11, 3805-3821.

12 D. Zhang, B. Gökce and S. Barcikowski, Chem. Rev., 2017, 117, 3990-4103.

13 D. Tan, S. Zhou, J. Qiu and N. Khusro, J. Photochem. Photobiol., C, 2013, 17, 50-68.

14 C. Byram and V. R. Soma, Nano-Struct. Nano-Objects, 2017, 12, 121-129.

15 Y.-H. Chen and C.-S. Yeh, Chem. Commun., 2001, 371-372.

16 M. Ganjali, M. Ganjali, S. Khoby and M. A. Meshkot, NanoMicro Lett., 2011, 3, 256-263.

17 G. C. Messina, M. G. Sinatra, V. Bonanni, R. Brescia, A. Alabastri, F. Pineider, G. Campo, C. Sangregorio, G. LiDestri and G. Sfuncia, J. Phys. Chem. C, 2016, 120, 1281012818.

18 M. Moskovits, Rev. Mod. Phys., 1985, 57, 783.

19 P. L. Stiles, J. A. Dieringer, N. C. Shah and R. P. Van Duyne, Annu. Rev. Anal. Chem., 2008, 1, 601-626.

20 J. S. Caygill, F. Davis and S. P. Higson, Talanta, 2012, 88, 1429.

21 R. Gillibert, J. Q. Huang, Y. Zhang, W. L. Fu and M. Lamy de la Chapelle, TrAC, Trends Anal. Chem., 2018, 105, 166-172.

22 G. K. Podagatlapalli, S. Hamad and S. V. Rao, J. Phys. Chem. C, 2015, 119, 16972-16983.

23 S. Scaramuzza, D. Badocco, P. Pastore, D. F. Coral, M. B. Fernández van Raap and V. Amendola, ChemPhysChem, 2017, 18, 1026-1034.

24 J. Ramyadevi, K. Jeyasubramanian, A. Marikani, G. Rajakumar and A. A. Rahuman, Mater. Lett., 2012, 71, 114-116. 
25 Y. Wei, S. Chen, B. Kowalczyk, S. Huda, T. P. Gray and B. A. Grzybowski, J. Phys. Chem. C, 2010, 114, 15612-15616.

26 J. R. Morones, J. L. Elechiguerra, A. Camacho, K. Holt, J. B. Kouri, J. T. Ramírez and M. J. Yacaman, Nanotechnology, 2005, 16, 2346.

27 K. Shin, D. H. Kim, S. C. Yeo and H. M. Lee, Catal. Today, 2012, 185, 94-98.

28 K. Chang and H. Chung, RSC Adv., 2016, 6, 75943-75950.

29 J.-P. Lee, D. Chen, X. Li, S. Yoo, L. A. Bottomley, M. A. ElSayed, S. Park and M. Liu, Nanoscale, 2013, 5, 11620-11624.

30 M. Sree Satya Bharati, C. Byram and V. R. Soma, Front. Phys., 2018, 6, 28.

31 S. Ibrahimkutty, P. Wagener, T. dos Santos Rolo, D. Karpov, A. Menzel, T. Baumbach, S. Barcikowski and A. Plech, Sci. Rep., 2015, 5, 16313.

32 S. Barcikowski, A. Menéndez-Manjón, B. Chichkov, M. Brikas and G. Račiukaitis, Appl. Phys. Lett., 2007, 91, 083113.

33 H. Ghaforyan, M. Ebrahimzadeh and B. Mohammadi, World Appl. Program, 2015, 5, 79-82.

34 K. Furusawa, K. Takahashi, H. Kumagai, K. Midorikawa and M. Obara, Appl. Phys. A: Mater. Sci. Process., 1999, 69, S359S366.

35 D. Mahl, J. Diendorf, S. Ristig, C. Greulich, Z.-A. Li, M. Farle, M. Köller and M. Epple, J. Nanopart. Res., 2012, 14, 1153.

36 Z. Swiatkowska-Warkocka, A. Pyatenko, F. Krok, B. R. Jany and M. Marszalek, Sci. Rep., 2015, 5, 9849.

37 H. Jiang, K. s. Moon and C. Wong, Synthesis of Ag-Cu alloy nanoparticles for lead-free interconnect materials, Proceedings. International Symposium on Advanced Packaging Materials: Processes, Properties and Interfaces, IEEE, 2005, pp. 173-177, DOI: 10.1109/ISAPM.2005.1432072.

38 M. Valodkar, S. Modi, A. Pal and S. Thakore, Mater. Res. Bull., 2011, 46, 384-389.

39 G. Compagnini, E. Messina, O. Puglisi and V. Nicolosi, Appl. Surf. Sci., 2007, 254, 1007-1011.

40 Z. Peng, B. Spliethoff, B. Tesche, T. Walther and K. Kleinermanns, J. Phys. Chem. B, 2006, 110, 2549-2554.

41 Y. Hashimoto, G. Seniutinas, A. Balčytis, S. Juodkazis and Y. Nishijima, Sci. Rep., 2016, 6, 25010.

42 S. Sebastian, C. Linslal, C. Vallbhan, V. Nampoori, P. Radhakrishnan and M. Kailasnath, Chem. Phys. Lett., 2015, 628, 25-29.

43 Z. Khan and A. Y. Obaid, RSC Adv., 2016, 6, 29116-29126. 44 P. Boyer, D. Ménard and M. Meunier, J. Phys. Chem. C, 2010, 114, 13497-13500.
45 S. Petrović, B. Salatić, D. Milovanović, V. Lazović, L. Živković, M. Trtica and B. Jelenković, J. Opt., 2015, 17, 025402.

46 P. Aazadfar, E. Solati and D. Dorranian, Opt. Mater., 2018, 78, 388-395.

47 A. Pyatenko, H. Wang, N. Koshizaki and T. Tsuji, Laser Photonics Rev., 2013, 7, 596-604.

48 Z. Swiatkowska-Warkocka, K. Koga, K. Kawaguchi, H. Wang, A. Pyatenko and N. Koshizaki, RSC Adv., 2013, 3, 79-83.

49 Y.-H. Chen, Y.-H. Tseng and C.-S. Yeh, J. Mater. Chem., 2002, 12, 1419-1422.

50 K. D. Malviya and K. Chattopadhyay, J. Phys. Chem. C, 2014, 118, 13228-13237.

51 S. S. B. Moram, C. Byram, S. N. Shibu, B. M. Chilukamarri and V. R. Soma, ACS Omega, 2018, 3, 8190-8201.

52 C. Byram, S. S. B. Moram, A. K. Shaik and V. R. Soma, Chem. Phys. Lett., 2017, 685, 103-107.

53 L. Xu, S. Li, H. Zhang, D. Wang and M. Chen, Opt. Express, 2017, 25, 7408-7417.

54 L. He, C. Liu, J. Tang, Y. Zhou, H. Yang, R. Liu and J. Hu, Appl. Surf. Sci., 2018, 434, 265-272.

55 L. Hu, Y. J. Liu, S. Xu, Z. Li, J. Guo, S. Gao, Z. Lu, H. Si, S. Jiang and S. Wang, Chem. Phys. Lett., 2017, 667, 351-356.

56 A. Hakonen, P. O. Andersson, M. S. Schmidt, T. Rindzevicius and M. Käll, Anal. Chim. Acta, 2015, 893, 1-13.

57 G. K. Podagatlapalli, S. Hamad, M. A. Mohiddon and S. V. Rao, Appl. Surf. Sci., 2014, 303, 217-232.

58 G. K. Podagatlapalli, S. Hamad, M. A. Mohiddon and S. V. Rao, Laser Phys. Lett., 2015, 12, 036003.

59 H. Syed, G. K. Podagatlapalli, M. Mohiddon and V. R. Soma, Adv. Mater. Lett., 2015, 6, 1073-1080.

60 C.-L. Zhang and Z. Li, Spectrosc. Spectral Anal., 2012, 32, 686690.

61 E. L. Holthoff, D. N. Stratis-Cullum and M. E. Hankus, Sensors, 2011, 11, 2700-2714.

62 P. Sajanlal and T. Pradeep, Nanoscale, 2012, 4, 3427-3437.

63 N. A. Hatab, C. Rouleau, S. T. Retterer, G. Eres, P. B. Hatzinger and B. Gu, Analyst, 2011, 136, 1697-1702.

64 A. Hakonen, F.-C. Wang, P. O. Andersson, H. Wingfors, T. Rindzevicius, M. S. Schmidt, V. R. Soma, S. Xu, Y. Li and A. Boisen, ACS Sens., 2017, 2, 198-202.

65 M. E. Farrell, E. L. Holthoff and P. M. Pellegrino, Appl. Spectrosc., 2014, 68, 287-296.

66 T. E. Acosta-Maeda, A. K. Misra, L. G. Muzangwa, G. Berlanga, D. Muchow, J. Porter and S. K. Sharma, Appl. Opt., 2016, 55, 10283-10289. 